\title{
Research and Practice on Teaching Reform of Public Art Education Elective Course Against the Background of "Internet Plus"
}

\author{
Yujing Zhang ${ }^{1, *}$ \\ ${ }^{1}$ Xi'an University of Technology, Xi'an, Shaanxi, China \\ *Corresponding author. Email: 1226437260@qq.com
}

\begin{abstract}
This study takes the public art education center as the basis and subject of implementation, and creates multidimensional aesthetic education while improving the course construction of "public art education elective course". In the specific implementation process, the "four classroom" linkage teaching model was first developed, that is, based on the first classroom, develop the second classroom, expand the third classroom, and open up the fourth classroom. Teaching resources and space can be expanded to create a new model of multidimensional aesthetic education that integrates and complements in-class and after-class, school and society, theoretical knowledge and artistic practice. Secondly, the teaching mode of "public art plus" should be constructed to properly combine public art with various disciplines and specialties, so as to break down the horizontal professional barriers of disciplines. Finally, it is necessary to excavate classic educational resources, enrich aesthetic education in colleges and universities, enrich public art education with national classics, strengthen cultural confidence, lead students to re-create theory in combination with practice, and improve the effectiveness of talent cultivation.
\end{abstract}

Keywords: Internet Plus, Public Art Education, Aesthetic education.

\section{INTRODUCTION}

The Chinese educator Mr. Cai Yuanpei once said, "one should first of all respect one's own culture; and also appreciate the culture of others for the prosperity of human civilization." Besides knowledge, the education of young people should also cultivate their aesthetic appreciation and the shaping of inner personality.

In essence, the beauty of harmony is a balance achieved by combining different beauties. There is no contradiction between adhering to individual beauty and pursuing the beauty of universal harmony, that is to say, "respect one's own culture" and "appreciate the culture of others" are

*Funds: This article is the "Innovative Research on the Integration of 'Four History' Elements into the Public Art Education System of Colleges and Universities", a Special Project of the Education Department of Shaanxi Provincial Government Science Research Program Approved in 2021 (Project Number: 21JK0245). Phased results of the 2021 Xi'an Social Science Planning Fund Project "Research on the Digital Art Performance of the Hua'e Xianghui Building Site Community of Tang Dynasty" (Project Number: WL242) complementary to each other, and the former is the premise and guarantee of the latter. Mr. Fei Xiaotong pointed out that we should be aware of the whole history of Chinese culture, have a clear understanding, self-knowledge, self-confidence, and have the ability of cultural transformation and the independent position of cultural choice.

\section{RESEARCH STATUS AND BACKGROUND ANALYSIS}

\subsection{Research Status and Background Analysis}

Aesthetic education is an education that cultivates students' ability to recognize, appreciate and create beauty [1]. As an important goal of public art education in colleges and universities, aesthetic education plays a pivotal role in improving students' personality, cultivating their sentiment and improving their humanistic quality. General Secretary $\mathrm{Xi}$ Jinping stressed in the 
National Education Conference that "we should comprehensively strengthen and improve aesthetic education in schools, adhere to aesthetic education and cultural education, and improve students' aesthetic and humanistic qualities" [2]. However, the informationization sweeping the world has made the Internet a "double-edged sword". On the one hand, life is more convenient and fast, and educational resources are more diversified. On the other hand, the information explosion has impacted contemporary people's audio-visual, and a large amount of information has flooded into the vision of Chinese youth. Especially with the spread of western culture, the values of college students in China are constantly impacted and affected by various trends of thought. Under such a background, it is particularly important to maintain independent judgment and rational aesthetic appreciation. As an important part of China's higher education system, public art curriculum is the main way for schools to implement aesthetic education [3]. Therefore, the teaching methods should be adjusted timely, the Internet resources should be used reasonably, the creative potential of students should be developed, the function of aesthetic education should be fulfilled actively, the personality of young people should be cultivated, the mental development should be improved, and their comprehensive ability should be enhanced.

\subsection{The Basis of Research Practice}

This paper is based on the public art education center of colleges and universities. At present, the center has 9 full-time music and art teachers, 16 part-time teachers, responsible for 52 art courses, including limited elective courses such as Introduction to Art and Music Appreciation, as well as optional elective courses such as Fundamentals of Oil Painting and Composition Art. The content covers works appreciation, art theory, traditional classics and other aspects.

As an important institution to carry out aesthetic education, the Public Art Education Center not only completes classroom teaching, but also actively carries out campus practice activities. It has successfully held a variety of exhibition activities such as "Public Art Education Video Exhibition", "Edecile Art into Campus", "Happy Youth • 2020 New Year Concert" and so on, which laid a good foundation for the research and practice of this project.

\section{RESEARCH OBJECTIVES AND TEACHING PROBLEMS TO BE SOLVED}

\subsection{Research Contents and Objectives}

Universities shoulder the responsibility of imparting professional knowledge and skills to college students [4], and are also an important front for cultural inheritance and cultural innovation. With the public art education center in colleges and universities as the main body, the course construction of "public art elective course" can be improved, the aesthetic education system can be optimized, and the special function of aesthetic education in colleges and universities can be fully played. On the one hand, college students' aesthetic experience, emotional experience, aesthetic pleasure and so on can be improved to enable young students to examine their own culture more comprehensively, more objective, more dialectical, more fully and deeply understand their own culture, so as to strengthen their cultural confidence; on the other hand, the correct direction of school aesthetic education can be followed by pooling resources and integrating forces, so that the vast number of young people can draw nutrition from the traditional culture of the Chinese nation, make use of the past for the present, have the courage to innovate, and further improve the training mode of innovative talents in colleges and universities.

\subsection{Teaching Problems to Be Solved}

\subsubsection{The Curriculum System Is Not Perfect}

At present, although a certain number of public art education elective courses are offered in many comprehensive classes, there are problems such as insufficient categories and limited class hours, which will restrict the acceptance degree of aesthetic education quality of college students. In the face of this problem, it is necessary to build a scientific and comprehensive school aesthetic education curriculum system by increasing and matching extracurricular art practice activities according to the school situation.

\subsubsection{Contradiction Between "Specialty" and "General Knowledge"}

Aesthetics courses are often professional. Disciplines, no matter fine arts, music, architecture or film and television, all need certain aesthetic 
cultivation and professional skills. For the science and engineering students who lack humanistic quality and aesthetic professional knowledge background, the low acceptance effect of communication is bound to reduce their interest in course selection to a certain extent. The art elective course should make clear the fundamental of "general education" and balance the contradiction between "specialty" and "general education".

\subsubsection{Contradictions Between Traditional Teaching and Talent Innovation}

In traditional teaching, the teacher is the center of the classroom, and the "teaching" of the teacher and the "learning" of the students are passive. At present, the cultivation of innovative talents needs to realize the organic combination of scale education and personalized training through the integration of interdisciplinary disciplines, and teach students in accordance with their aptitude. It is necessary to make full use of the integration of aesthetic theory and creative practice, and the mutual care of art and major, so as to improve students' innovation ability and improve the construction of multi-talent training system.

\section{RESEARCH IDEAS AND IMPLEMENTATION METHODS}

\subsection{Research Ideas}

\subsubsection{Enriching Public Art Education with National Classics and Strengthening Cultural Confidence}

In public art courses, national classics should be introduced as an important means and approach to realize "cultural inheritance and innovation", so as to form a universal mechanism of curriculum teaching, practical activities, campus culture and art performance. School conditions, talent training methods and professional structures of different majors, group advantages and interdisciplinary characteristics, as well as students' actual needs of aesthetic taste are all taken into consideration to explore the inheritance and development of excellent traditional Chinese culture, so that students can further strengthen their cultural confidence.

\subsubsection{Enhancing Students' Comprehensive Quality and Stimulating Their Innovative Ability by Stereoscopic Aesthetic Education}

Diversified aesthetic education approaches can be employed to stimulate students' creative potential and cultivate young people's innovative thinking. Famous scientist Qian Xuesen stressed that "scientists are not craftsmen, and there should be art in the knowledge structure of scientists, because there is aesthetics in science" [5]. The interdisciplinary public art education teaching activities with aesthetic education as the theme organically integrate humanity, nature and artistic aesthetics, explore the professional talent training mode with humanistic quality, and thus promote the creative transformation and innovative development of excellent traditional Chinese culture [6] ("Figure 1"). 


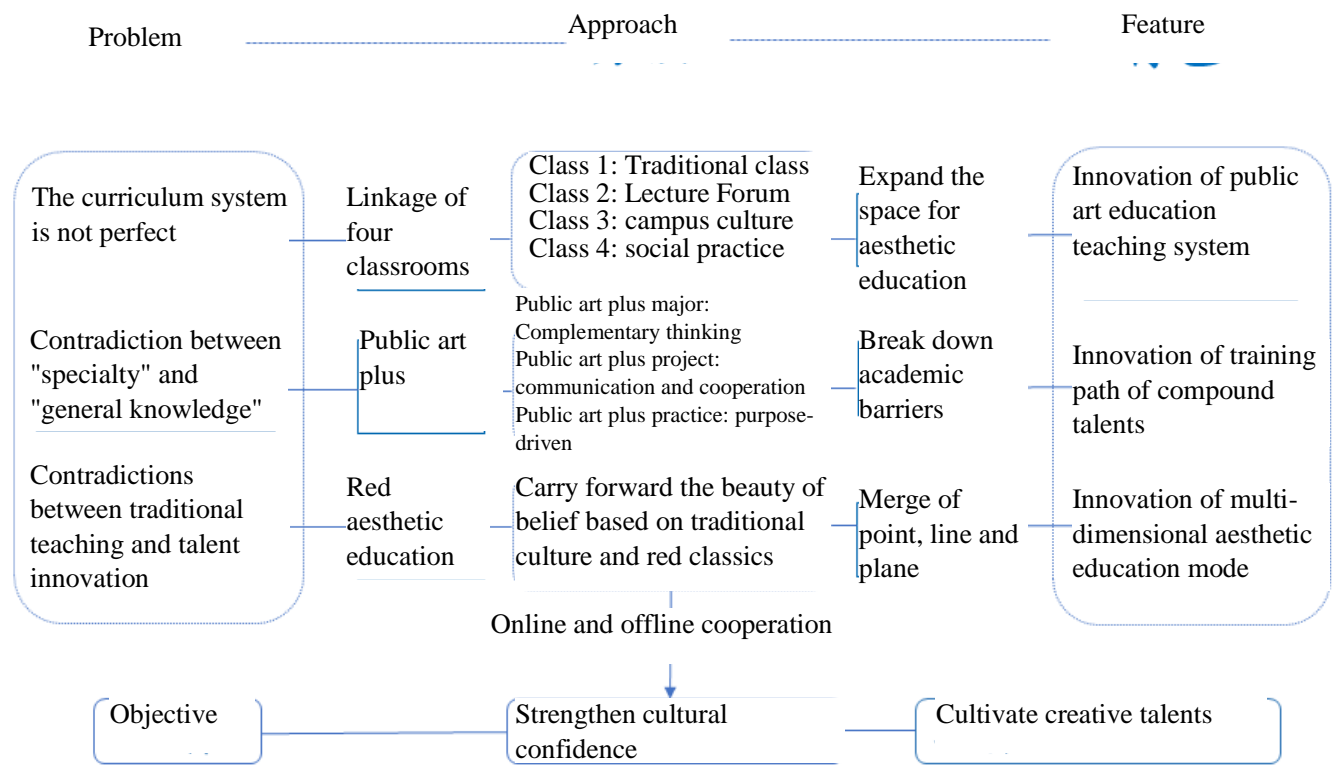

Figure 1 Case study.

\subsection{Implementation Method}

\subsubsection{Perfecting the Course Construction of "Public Art Education Elective Course", Creating Multi-dimensional Aesthetic Education}

Traditional classroom teaching content should be enriched to base on the first classroom; "Public Art Education Forum" should be used to invite famous teachers and experts to impart knowledge and develop a second classroom. Campus cultural activities such as college students' art associations and the introduction of elegant art into the campus can also be carried out to expand the third classroom. Taking the opportunity of the art experiment project of "Breaking through the Fences - Star World", the school has established a public art education practice and service base outside the school, and opened up the fourth classroom. The linkage of "four classes" expands teaching resources and space, and creates a new model of multi-dimensional aesthetic education that integrates and complements in-class and after-class, school and society, theoretical knowledge and art practice.

\subsubsection{Building the Teaching Mode of "Public Art Plus" to Break Down the Barriers of Disciplines and Professions}

In view of the universal contradiction between "professionalism" and "generality", on the one hand, the teaching content of "public art education elective course" should be adjusted actively to select the art theme in line with the current college students' universal aesthetic appreciation; On the other hand, more diverse forms of art elective courses should be opened to provide diverse choices for students of different majors.

Taking public art as the platform, the "interdisciplinary" characteristics of its elective courses are brought into play, and through public art plus major, complementary thinking is formed to stimulate students' innovative thinking. The Public Art plus program helps to form an "art project group" that encourages students from different disciplines to communicate with each other and fill in their knowledge gaps. Public art plus practice has also been implemented to provide students with a variety of approaches to art practice and break the inherent teaching mode. In the specific teaching process, the "public art plus" teaching mode will continue to be expanded to break down professional barriers and further cultivate interdisciplinary talents. 


\subsubsection{Digging Chinese Classical Education Resources and Enriching Aesthetic Education in Colleges and Universities}

Chinese traditional classics should be explored to explore the beauty of Oriental art, boost the connotation of aesthetic education, and feel the beauty of Chinese classical culture through various art forms such as music, fine arts and films. Chinese classic art resources are used as a basis to carry out cultural education. While offering relevant elective courses of public art, students' community activities are organized to build campus cultural brands.

\section{RESEARCH RESULTS}

\subsection{Innovating the Teaching Mode and Creating the Brand of Public Art Education}

Through the original mode of "Public Art plus" and "Diversified Three-dimensional Aesthetic Education", this project, on the one hand, explores the connotation of the course deeply; on the other hand, expands the space of aesthetic education, and actively transforms it into paper results in teaching practice, so as to build its own brand of aesthetic education, and to some extent, provides a reference model for quality-oriented education for other universities.

\subsection{Internet Plus Aesthetic Education, Online and Offline Joint Promotion}

Online and offline aesthetic education resources should be integrated to actively hold and participate in online and offline performances and exhibitions and other art activities, and use various media of the Internet to display and spread in the cloud, so as to further expand the influence of public art education in our school.

\subsection{Aesthetic Education Teaching Combines Social Practice to Cultivate Innovative Composite Talents}

In the present society, higher education has shown a trend of multidisciplinary intersecting and integration. Therefore, it has become important for higher education to cultivate high-quality interdisciplinary and innovative talents to meet the development needs of the current social situation.
This project puts forward a training program of public art education plus major plus social practice to lead students to re-create with theory combined with practice, and improve the effectiveness of talent cultivation.

\section{INNOVATION POINTS}

\subsection{Innovation of Public Art Education Teaching System}

In the process of improving the aesthetic education promotion mechanism of "four in one" including curriculum teaching, practical activities, campus culture and art performance, a unique "four classroom linkage" is constructed to bring aesthetic education-led public art education and teaching from books to life, from classroom to campus, and from school to society.

\subsection{Innovation of Training Path of Compound Talents}

The mode of combining theory with practice of public art education should be emphasized. Through artistic edification and emotional inspiration, the perceptual thinking training and rational thinking should be developed in a balanced way, and innovative talents with highly cultural, artistic and scientific characteristics should be cultivated, so as to provide students with a broad space for sustainable improvement.

\subsection{Innovation of Multi-dimensional Aesthetic Education Mode}

"Public art education" is carried out, public art elective courses are used to connect students' majors, and public art project groups are used as platforms to attract students from different majors and break through discipline barriers. Through teaching and practice, points, lines and surfaces are fused together to form a new pattern of multidimensional aesthetic education.

\section{CONCLUSION}

On the one hand, the exploration and practice of public art education system in colleges and universities can cultivate students' sound and diversified personality quality, and stimulate young people's perception of beauty in aesthetic guidance and general education. On the other hand, the integration of courses, associations, performances and social practice greatly expands the educational 
resources and potential of colleges and universities. In the process of teaching and learning, seeing and understanding, it not only cultivates innovative talents in the new era, but also hones the teaching team, improves the teaching quality of schools and shapes the brand of aesthetic education.

\section{AUTHORS' CONTRIBUTIONS}

This paper is independently completed by Yujing Zhang.

\section{REFERENCES}

[1] Zhao Silin, Zhu Dequan. On Raising Strategies of Mathematics Intuitive Thought [J]. Journal of Mathematics Education, 2010, 02(19): 23-26. (in Chinese)

[2] Che Kuai. A Brief Talk on the Reform of Commercial Photography Courses for University Photography Majors in the New Media Era [J]. Research on Transmission Competence, 2018, 2(36): 184. (in Chinese)

[3] Mao Xiaohua. Public Art Education in University in the Threshold of Ethnics [J]. Hundred Schools In Art, 2013, 29(S2): 420422. (in Chinese)

[4] Liu Jing, Li Guishan. A Study of College Students' Cultural Self-Confidence in the Multicultural Perspective [J]. Theory and Practice of Education, 2013, 06(33): 12-13. (in Chinese)

[5] Li Qingju. Study of Cai Yuanpei's "Substituting Aesthetic Education for Religion" [D]. Nanjing: Nanjing University of Science and Technology, 2012. (in Chinese)

[6] Li Xinchao, Fan Peng. Review and Prospects of the Research on Creative Transformation and Innovative Development of Chinese Excellent Traditional Culture [J]. Cultural Soft Power, 2020, 5(03): 74-82. (in Chinese) 